\title{
MODEL STRATEGI MANAJEMEN KEBIJAKAN PUBLIK SEKTOR PASAR TRADISIONAL UNTUK PENINGKATAN PENDAPATAN ASLI DAERAH DI KABUPATEN BENGKAYANG KALIMANTAN BARAT
}

\author{
Yulita $^{1}$, Cakti Indra Gunawan ${ }^{2}$ \\ ${ }^{12}$ Universitas Tribhuwana Tunggadewi \\ yulitaputrikumpot@gmail.com
}

\begin{abstract}
Public policy in the traditional market sector is currently an important element for efforts to increase local revenue (PAD). The impact of PAD will encourage community welfare and strengthen regional finance. The purpose of this study is 1) To analyze the management of the traditional market sector public policy strategy that has been carried out by the Government of Bengkayang Regency, West Kalimantan 2) To explore the proposed strategic management model for increasing PAD in Bengkayang district. The research method used is descriptive qualitative with a SWOT analyst tool. This research finding shows that the public culture of the traditional market sector in Bengkayang district is still not able to contribute to a significant increase in PAD. The management strategy used so far is still non-technology based. With the proposed strategy management model of integrated market management strategy, it will be one of the solutions in increasing PAD in Bengkayang district.

\section{Keywords: Strategic Management, Public Policy, Regional Original Income, Traditional Market} Sector

\section{ABSTRAK}

Kebijakan publik sektor pasar tradisional saat ini menjadi elemen penting untuk upaya peningkatan pendapatan asli daerah (PAD). Dampak dari PAD akan mendorong kesejahteraan masyarakat dan menguatkan keuangan daerah. Tujuan penelitian ini adalah 1) Menganalisis manajemen strategi kebijakan publik sektor pasar tradisional yang telah dilakukaan oleh Pemerintah Kabupaten Bengkayang Kalimantan Barat 2) Mengeksplorasi usulan model manajemen strategi yang efisien untuk peningkatan PAD di kabupaten Bengkayang. Metode penelitian yang digunakan adalah deskriptif kualitatif dengan alat analis SWOT. Temuan penlitian ini menunjukkan bahwa kebiakan publik sektor pasar tradisional di kabupaten Bengkayang masih belum mampu memberikan kontribusi peningkatan PAD yang signifikan. Manajemen strategi yang digunakan selama ini masih bersifat non-technology based. Dengan usulan model manajemen strategi integrated market management strartegic akan menjadi salah satu solusi dalam peningkatan PAD di kabupaten Bengkayang.
\end{abstract}

Kata Kunci: Manajemen Strategi, Kebijakan Publik, PAD, Sektor Pasar Tradisional 


\section{PENDAHULUAN}

Kebijakan publik sebagaimana ditekankan oleh Wilson (2019:45) menunjukkan usaha sungguh-sungguh yang dilakukan oleh pemerintah untuk mensejahterakan masyarakat melalui peraturan daerah atau undang-undang yang menjadi payung pelaksanaan sebuah kebijakan. Di sisi lain Gunawan (2015: 23) memberikan penjelasan tentang bagaimana pengelolaan sebuah sistem kebijakan yang dilakukan oleh pemerintah pusat maupun daerah, diperluka integrated policy dan kesatuan langkah dalam sistem informasi yang dapat dikontrol besama oleh publik baik pemerintah dan aparaturnya maupun oleh masyarakat sasaran itu sendiri.

Pemerintah Kabupaten Bengkayang Kalimantan Barat telah melakukan upaya peningkatan pendapatan asli daerah (PAD), yang salah satunya adalah peningkatan pelayanan pasar tradisional. Tanpa adanya upaya yang serius dari pemerintah tentu hal ini akan melemahkan layanan publik dan kebijakan publik itu sendiri tidak dapat dijalankan dengan maksimal (Azis, 2018). Untuk itu manajemen strategi sebagai salah satu alat untuk mencapai tujuan kebijakan publik yang efektif dan efisien yang ada di kabupaten Bengkayang dapat dilakukan secara simultan dan sustainable.

Potensi ekonomi yang ada di kabupaten Bengkayang menurut data dari Badan Pusat Statistik (BPS) (2019), lebih dari $50 \%$ kebutuhan masyarakat Bengtkayang masih didominasi kebutuhan pangan yang di dalamnya melibatkan hasil pertanian seperti padi-padian, ubi, sayursayuran dan hasil perikanan darat. Hal ini menunjukkan potensi pasar tradidional di Kabupaten Bengkayang menjadi aset yang penting untuk peningkatan Pendapatan Asli Daerah.

Beberapa penelitian yang telah dilakukan oleh peneliti terdahulu tentang manajemen pengelolaan pasar dan upaya peningkatan pendapatan asli daerah antara lain Mubarok (2016) yang memfokuskan pada retribusi pasar dan pengelolaan keuangan serta aset daerah di Samarinda. Selain itu Fajarwati (2017) mengkaji strategi retribusi pasar di Bekasi. Sedangkan Jatmika (2017) meneliti kebijakan publik sektor pasar tradisional di kota Probolinggo. Penelitian yang mengkaji Empowerment of Traders and Traditional Market Potential Development in Indonesia dikaji oleh Sahban \& Perwira, 2018 .

Kajian tentang pengelolaan pasar yang telah diteliti oleh penelit-peneliti tersebut belum ada yang membahas manajemen strategi kebijakan publik yang fokus pada Perda Pasar dan pengeloaan manajemen pasar berbasiskan teknologi online salam sebuah model strategi. Di sinilah peneliti mengisi gap of research yang masih sedikit dbahas oleh penelitipeneliti sebelumnya.

\section{TINJAUAN PUSTAKA}

\section{Manajemen Strategi}

Prasojo (2018:10) mendefinisikan manajemen strategi sebagai upaya untuk mempengaruhi sebuah rencana dapat dijalankan dengan efektif dan efisien untuk kepentingan bersama. Sedangkan Yunus (2016: 12) lebih mengedepankan manajemen strategi untuk trik atau cara yang tepat agar program-program kerja dapat dilaksankan dengan maksimal dan mencapai sasaran atau tujuan yang diinginkan.

Di sisi lain Wheelen (2010:17) menjelaskan bahwa manajemen strategi adalah serangkaian keputusan managerial dan upaya yang dilakukan untuk menentukan keberhasilan sebuah organisasi dalam jangka panjang. Dengan definisi tersebut maka dapat dijabarkan manfaat manajemen strategi sebagai berikut: a) dapat menghasilkan tindakan yang efektif dan efisien untuk mencapai tujuan b) Menghasilkan keputusan terbaik 
dan bersifat strategis c) Mengurangi permasalahan pada saat implementasi sebuah rencana dan kebijakan

\section{Kebijakan Publik}

Menurut Taufiqurrokhman (2014:3) mengatakan bahwa kebijakan publik adalah bagaimaan aktor dari sebuah pemerintahan dapat mengelola sebuah kebijakan dan dpat bemanfaat bagi masayarakat. Sedangkan Wilson (2019:14) menegaskan bahwa kebijakan publik adalah upaya pemerintah baik di pusat maupun di daerah untuk mengelola sebuah kebijakan yang dimulai dari perencanaan hingga implementasi agar bedampak positif bagi masyarakat secara luas.

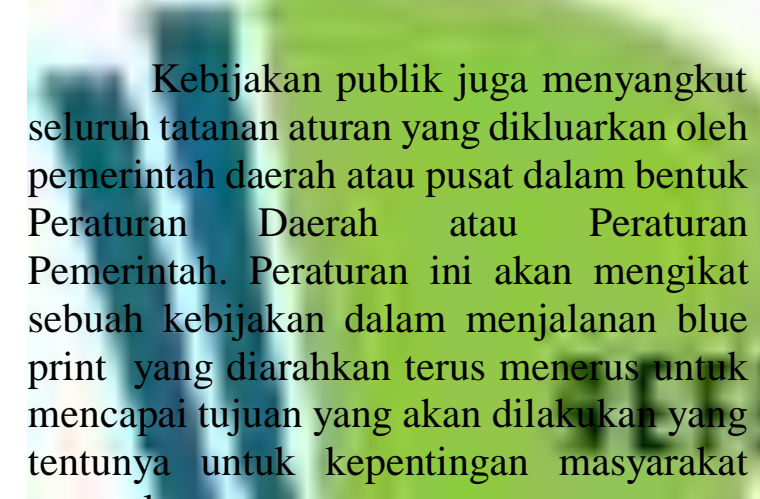
secara luas.

\section{Pasar Tradisional}

Pasar tradisional merupakan tempat jual beli barang-barang yang diperdagangkan oleh penjual di sebuah tempat yang disediakan resmi oleh pemerintah daerah. Pasar tradisional berbeda dengan pasar modern seperti Mall dan pasar modern lainnya.

Sedangkan retribusi pasar menurut Sudaryo (2017) merupakan retribusi yang diberikan oleh pengelola pasar untuk kepentingan peningkatan pendapatan daerah. Retribusi pasar sangat erat kaitannya dengan pendapatan asli daerah, di mana sisi pemasukan yang rutin dari pasar tidak dapat dipungkiri sebagai salah satu cerminan pendapat yang rutin dan dapat diperoleh melalui payung Peraturan Daerah (PERDA) di setiap daerah (Menkeu, 2017).
Menurut Toduho (2014), retribusi pasar merupakan salah satu retribusi daerah yang termasuk dalam jenis retribusi jasa umum. Oleh karena itu dalam retribusi pasar, prinsip dan sasaran dalam penetapan struktur dan besarnya tarif retribusi pasar didasarkan pada tujuan untuk memperoleh keuntungan yang layak sebagai pengganti biaya pengelolaan, biaya penyelenggaraan, biaya kebersihan dan biaya administrasi

\section{Pendapatan Asli Daerah}

Pendapatan asli daerah (PAD) menurut Temaja, 2014) adalah kemampuan daerah untuk membiayai kegiatan rutin maupun pembangunan). Penerimaan Pendapatan Asli Daerah merupakan akumulasi dari Pos Penerimaan Pajak yang berisi Pajak Daerah dan Pos Retribusi Daerah, Pos Penerimaan Non Pajak yang berisi hasil perusahaan milik daerah, Pos Penerimaan Investasi serta Pengelolaan Sumber Daya Alam (Bastian, 2002).

Menurut Toduho
Pendapatan Asli Daerah (PAD) merupakan
penerimaan pengenaan, retribusi,
pengelolaan kekayaan wilayah yang terputus-putus dan milik orang lain. Retribusi daerah merupakan salah satu sumber keuangan pembangunan yang mengandalkan pemanfaatan kembali otonomi daerah.

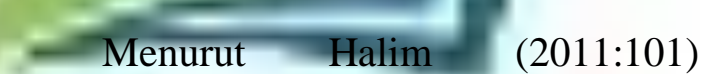

pengertian Pendapatan Asli Daerah merupakan semua penerimaan daerah yang berasal dari sumber ekonomi asli daerah. Pendapatan Asli Daerah dipisahkan menjadi empat jenis pendapatan, yaitu pajak daerah, retribusi daerah, hasil perusahaan milik daerah dan hasil pengelolaan kekayaan milik daerah yang dipisahkan, lain-lain Pendapatan Asli Daerah yang sah. Pendapatan Asli Daerah (PAD) secara ringkas adalah penerimaan hasil dari setoran pajak daerah, retribusi daerah hasil dari milik daerah, hasil pengelolaan kekayaan daerah yang dipisahkan dan lain-lain pendapatan asli daerah yang sah. Sebagaimana disebutkan 
bahwa pendapatan asli daerah merupakan penerimaan daerah yang berasal dari berbagai sumber ekonomi asli daerah, maka diharapkan setiap pemerintah daerah dapat membangun infrastruktur ekonomi baik di daerahnya masing-masing guna meningkatkan pendapatannya.

\section{METODE}

Metode penelitian yang digunakan dalam penelitian ini adalah dengan menggunakan penelitian deskriptif kualitatif. Peneliti memfokuskan pada kebijakan pemerintah kabupaten Bengkayang dalam menangani manajemen pengelolaan pasar tradisional yang ada di daerah tersebut. Data yang diambil adalah data primer dan sekunder. Data primer diperoleh dari hasil wawancara dengan pengelola pasar di Kota Bengkayang, para pedagang pasar, dinas pendapatan dan dinas pasar kabupaten Bengkayang. Data sekunder diperolah dari laporan pemerintah kabupaten Bengkayang serta literatur baik dari buku maupun dari jurnal ilmiah. Alat analisis yang digunakan adalah dengan menggunakan metode SWOT analysis.

Data yang terkumpul dari kajian pustaka dengan cara mengkomparasikan dokumen dan pendapat para ahli tentang bagaimana meningkatkan pendapatan asli daerah dari sisi pasar tradisional. Dengan teknik library research comparation akan memunculkan suatu substansi keilmuan baru yang dapat memberikan kontribusi keilmuan di bidang kebijakan publik. Sugiono (2016) menyatakan bahwa dengan studi komparasi literarur akan dapat dipaparkan data beserta sumbangan para ilmuwan agar mampu melihat dan menganalisa dengan jelas sebuah substansi keilmuan yang diteliti. Dengan komparasi ini, memudahkan peneliti untuk mencarai cara dalam keilmuan yang baru dan dapat dikatakan novelti.

\section{HASIL DAN PEMBAHASAN}

\section{Strategi manajemen kebijakan publik dalam pengelolaan pasar di kabupaten Bengkayang}

Menuut data lapangan yang diperoleh dari wawancara dengan para pedagang pasar, petugas UPT Pasar, Dinas Pendapatan dan Dinas Pasar kabupaten Bengkayang, manajemen kebijakan publik dalam pengelolaan pasar masih tergolong kurang maksimal. Hal ini dibuktikan belum adanya Perda yang khusus membahas pengelolaan pasar secara serius. Misalnya belum adanya penanganan kebersihan yang teratur di lingkungan pasar, masih kurang profesional penataan kios-kios pasar dan masih banyak praktek pungli yang dilakukan oleh oknum-oknum pemerintah kepada pedagang pasar.

Berdasarkan analisis SWOT dapat dijabarkan posisi kebijakan publik sektor pasar di kabupaten Bengkayang pada posisi cenderung lemah secara strategis, dibandingkan dengan kekuatan potensi retribusi pasar yang diharapkan dapat meningkatkan PAD di kabupaten Bengkayang. Target retribusi pasar setiap tahun sampai 2018 hanya mencapai 45\%. Hal ini masih banyak kebocoran yang dilakukan oleh petugas pasar dan tidak transparan dan dana yang mengalir ke kas pendapatan daerah belum bisa maksimal.

Kelebihan yang ada dalam manajemen pengelolaan pasar adalah sudah terbentuknya pasar tradisional di 17 kecamatan di kabupaten Bengkayang. Di mana masing-masing pasar memiliki potensi kuat untuk melakukan transaksi ekonomi dari hasil panen para petani dan dijual di pasar. Potensi alam yang mendukung hasil pertanian sangat signifikan untuk pertumbuhan pasar secara makro ekonomi. Segala jenis hasil produksi pertanian tersedia di pasar-pasar kecamatan di kabupaten Bengkayang.

Kelemahan yang nampak dalam pengelaan pasar adalah tidak adanya payung secara hukum melalui Perda yang jelas dalam pengelolaan pasar. Hal ini kurang didukung oleh dewan perwakilan rakyat daerah (DPRD) kabupaten bengkayang yang belum mendorong produk hukum Perda secara maksimal dalam pengelolaan pasar secara modern 
dan tranparan. Perda No 5 tahun 2010 tentang pengelolaan pasar di kabupaten bengkayang memang sudah ada, namun belum ada pasal-pasal yang kuat untuk pengelolaan secara transparan dan menggunakan sistem online untuk pelaporan pengelolaannya. Kelemahan lain adalah kurang adanya integrasi antara pedagang pasar dan pengelola pasar, dalam arti tidak adanya koordinasi yang jelas dalan penjualan dan penggunaan kios-kios yang ada di pasar. Sehingga kesemrawutan terjadi, dan pasar sangat kotor serta tidak mencerminkan manajemen pengelolaan pasar tradisional yang telah maju seperti dicanangkan oleh Presiden jokowi dalam pengelolaan pasar tradisional sebagai tulang punggung ekonomi rakyat.

Adapun peluang yang dapat dilihat adalah memungkinkannya pengembangan 17 pasar tradisional di kabupaten Bengkayamg menjadi pasar yang lebih maju dan profesional seperti yang telah digagas oleh presiden Jokowi misalnya pasar tradisional di Solo, Purwokerto dan kota-kota lain di Jawa yang sudah menunjukkan pasar tradisional yang reprentatif dan pengelolaan yang transparan serta dapat dipertanggungjawabkan secara finansial untuk mendukung PAD di daerah.

Ancaman yang terjadi dalam manajemen pengelolaan pasar bila tidak didukung oleh kebijakan publik yang kuat dan memiliki passion yang kuat, maka pasar tradisional di kabupaten bengkyang akan tergusur dan kalah dengan pasar modern yang merebak dan muncul di setiap sudut kecamata, misalnya pasar swalayan, indomaret, alfamaret yang lengkap dengan segala jenis produk yang dijual. Bahkan istana sayur juga menyediakan hasil pertanian yang lebih modern dan tertata secara manajemen.

\section{Model manajemen terintegrasi pengelolaan pasar}

Model manajemen strategi yang diterapkan dalam pengelolaan pasar masih kurang maksimal. Dengan demikian peneliti menemukan model baru dalam pengelolaan pasar yaitu dengan integrated market management strategic yang berbasiskan kebijakan publik yang transparan dengan sistem online. Dalam model ini setiap pedagang pasar dapat bebas berjualan dan secara periodik membayar retribusi kepada pengelola pasar. Pengelola pasar akan meneruskan pembayarannya ke dinas pendapatan dan diawasi oleh dinas pasar secara terintegrasi.

Dengan model terintegrasi ini, maka arus keuangan dari retriubsi akan nampak mampu mendukung peningkatan PAD kabupaten Bengkayang, dan secara manajemen penglelolaan pasar akan mampu menghasilkan pasar tradisional namun lebih modern, rapi, tidak kotor dan menarik pembeli yang datang ke pasar tersebut. Pasar modern akan dapat diredam dan bersing ketat dengan pasar tradisional apabila pasar tradisional dapat dikelola secara makismal berbasiskan website yang disediakan oleh pemerintah kabupaten Bengkayang dalam setiap pelaporan dan pengelolaannya,

Di bawah ini akan disampaikan model baru manajemen strategi pengelolaan pasar. 

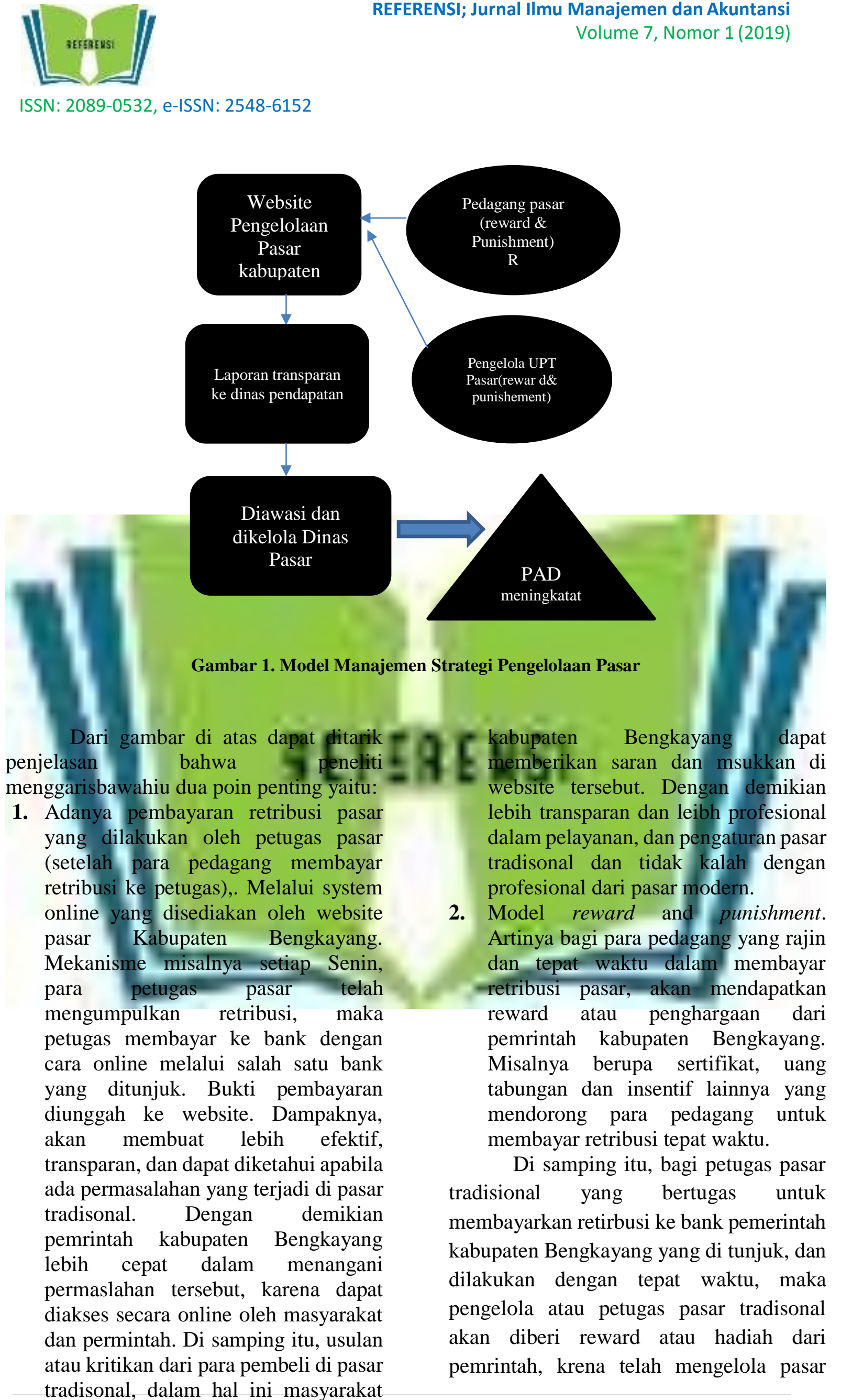
tradisional dengan baik dan benar. Bagi yang terlambat membayar retribusi maka aka ada paunishement atau hukuman. Misalnya tidak boleh lagi berdagang di

\section{KESIMPULAN}

1. Manajemen strategi kebijakan publik sektor pasar di kabupaten Bengkayang masih belum maksimal dalam pengelolaannya. Hal ini ditengarai dengan adanya kurang dukung Perda yang mengatur pasar tradisional secara maksimal dan modern. Perda no 5 tahun 2010 tentang pengelolaan pasar masih kurang menjadi kebijakan publik yang belum maksimal daalam pengelolaan dan tata kelola secara transparan berbasis online Melalui analisis SWOT nampak bahwa kekuatan yang ada dalam pengelolaan pasar masih banyak kekurangannya. Hal ini akan bedampak pada ancaman pasar daerah (pasar tradisional) yang akan kalah saing dengan pasar swasta atau pasar modern.

2. Model integrated market management strategic merupakan temuan peneliti untuk pengelolaan pasar tradisional yang lebih tranparan, online dan terintegrasi antara pedagang pasar, pengelola pasar dan dinas pendapatan serta dinas pasar. Dengan sistem reward and punishment memungkinkan pelaku pedagang pasar akan berlomba lomba dalam menata kiosnya secar bersih, rapi, teratur dan selalu tepat waktu dalam pembayaran retribusi pasar sehingga akan mendorong peningkatan PAD yang signfikan di kabupaten Bengkayang. Sistem ini juga mendorong pihak pengelola pasar akan semakin intens dan seirus untuk memajukan pengelolaan pasar sehingga dampak ekonomi dapat dirasakan secar luas dan mampu bersaing dengan pasar modern atau pasar swasta lainnya di kabupaten Bengkayang pasar tradisonal tersebut. Atau misalnya dipidnahkan ke tempat lain atau kebijakan lain sehingga membuat pedagang pasar menjadi jera.

\section{Saran}

1. Bagi pemerintah

Permerintah Kabupaten Bengkayang didorong segera mengeluarkan perda pasar tradisional yang akan menjadi payung hukum untuk pelaksanaan kebijakan publik sektor pasar tradisinal. Dengan adanya perda dan sistem informasi berbasiskan online terintegrasi antara dinas pendapatan, dinas pasar dan UPT pasar, maka memudahkan pemantauan dalama retribusi pasar. Pendapatan Asli daerah akan semakin meningkat jika dipicu oleh model manajemen strategi yang lebih terintegrasi.

2. Bagi pedagang

Pedagang pasar didorong untuk menjaga kebersihan pasar, kerapian dan keamanan selama berdagang di pasar. Dengan demikian-akan mendorong pasar tradisional lebih "modern" dan rapi serta mampu menuaskan pembeli. Di samping itu juga akan meningkatkan daya jual dan mampu besaing dengan pasar modern yang ada di Kabupaten Bengkayang.

3. Peneliti selanjutnya

Peneliti selanjutnya diharapkan mampu meneliti lebih dalam lagi dari sisi manfaat online integrated yang dapat menggunakan alat analisis kuantitatif dengan menggunakan sampel yang memenuhi syarat untuk perhitungan dengan analisis regresi berganda atau analisis kuantitif statistik lainnya.

\section{DAFTAR PUSTAKA}

Badan Pusat Statistik Kabupateng Bengkayang. Sensus Ekonomi. BPS Bengkayang

Caroline, (2005), Analisis Kinerja Penerimaan Retribusi Pasar di Kota Salatiga, Tesis, Universitas Diponegoro, Semarang.

Damanik, KI., Siregar, T.R, (2010). 


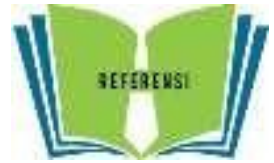

ISSN: 2089-0532, e-ISSN: 2548-6152

dan Masa Depan Indonesia. Yayasan

Pustaka Obor Indonesia, Jakarta.

Dessy Ayuni M. Toduho, David Paul Elia Saerang \& Inggriani Elim. (2014). Penerimaan retribusi pasar dalam upaya meningkatkan pendapatan asli daerah kota tidore kepulauan, Jurnal EMBA, Vol.2 No.2, pp. 1090-1103.

Fajarwati, D. (2017). Evaluasi Pengelolaan

Retribusi (Studi Kasus pada Pasar Bantar Gebang Kota Bekasi). Jurnal JRAK. Vol. 8 No. 2, pp. 153-177.

Gunawan, Cakti, I. (2015). Sistem Informasi managemen dan $e$ Government. CV.IRDH: Purwokerto. Halim, A. (2007). Akuntansi Keuangan Daerah. Penerbit Salemba Empat: Jakarta

Haris, S. (2007). Desentralisasi dan Otonomi Daerah. LIPI Press: Jakarta. Isfatul Fauziah, Achmad Husaini, M. Shobaruddin, Analisis Kontribüsi Penerimaan Pajak Daerah Sebagai Salah Satu Sumber Pendapatan Asli Daerah (Pad) Kabupaten Malang (Studi Pada Dinas Pendapatan Pengelolaan Keuangan Dan Aset Kabupaten Malang). V Jurnal Perpajakan. Vol. 3 No. 1, pp. 1-7.

Jatmika, Pungky, P. (2017). Kebijakan Pemerintah Daerah Dalam Pengelolaan Pasar Tradisional Di Kota Probolinggo. Jurnal SAWALA. Vol 5 No 2, pp. 35-47

Mubarok, Fharma, H. (2016) Potensi Penerimaan Retribusi Pelayanan Pasar Dan Kontribusi Serta Prospeknya Terhadap Pendapatan Asli Daerah Kota Samarinda. FORUM EKONOMI: Jurnal Ekonomi, Manajemen dan Akuntansi, Volume 18, No.2. pp. 95-110.

Nasharuddin Mas, Armanu Thoyib, Surachman \& Solimun, (2014).
Trader Sturdiness at Traditional Market in Facing Modern Market Progress. International Journal of Business and Management Invention, Vol.3, No.5: pp. 49-58.

Noviati Putri Wardani (2010) tentang "Pengaruh Retribusi Pasar dengan Retribusi Persampahan terhadap PAD Kabupaten Sidoharjo."

Pemerintah kabupaten Bengkayang. Perda No. 5 tahun 2010 tentang Pengelolaan Pasar Kabupaten Bengkayang.

Prasojo, L.D. (2018). Manajemen Strategi. UNY Press: Yogyakarta

Prastyawan, A; Agus Suryono, M. Saleh Soeaidy \& Khairul Muluk, (2015). Revitalization of Traditional Markets into a Modern Market in the Perspective of Local Governance Theory. Journal of Humanities And Social Science. Vol 20, pp. 01-06. Sahban, +H \& Perwira, I. (2018). Empowerment of Traders and Traditional Market Potential Development in Indonesia, International Journal of Innovative Science and Research Technology, vol. 3 No. 1 pp. 428-436.

Sudaryo, S.S, (2017). Keuangan dan Otonomi Daerah. Andi Offset: Yogyakarta.

Sugiyono. (2016) Metode Penelitian Kuantitatif dan Kualitatif QR. Penerbit Alfabeta: Jakarta.

Toduho, Dessy, A; Saerang, D.P \& Elim, I. (2014). Penerimaan Retribusi Pasar Dalam Upaya Meningkatkan Pendapatan Asli Daerah Kota Tidore Kepulauan. Jurnal EMBA. Vol 2. No. 2, pp. 1090-1103.

Wheelen, Thomas L., Hunger, J. David, (2010) Strategic Management and 


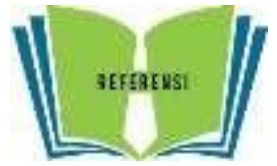

ISSN: 2089-0532, e-ISSN: 2548-6152
Business
Policy
Achieving
Sustainability.
Twelfth
Edition.
Pearson

Wilson, C.A. (2019). Public Policy.

Waveland Press, Incorporated: USA.

Yunus, Eddy. (2016). Manajemen

Strategis. CV. ANDI Offset:

Yogyakarta.

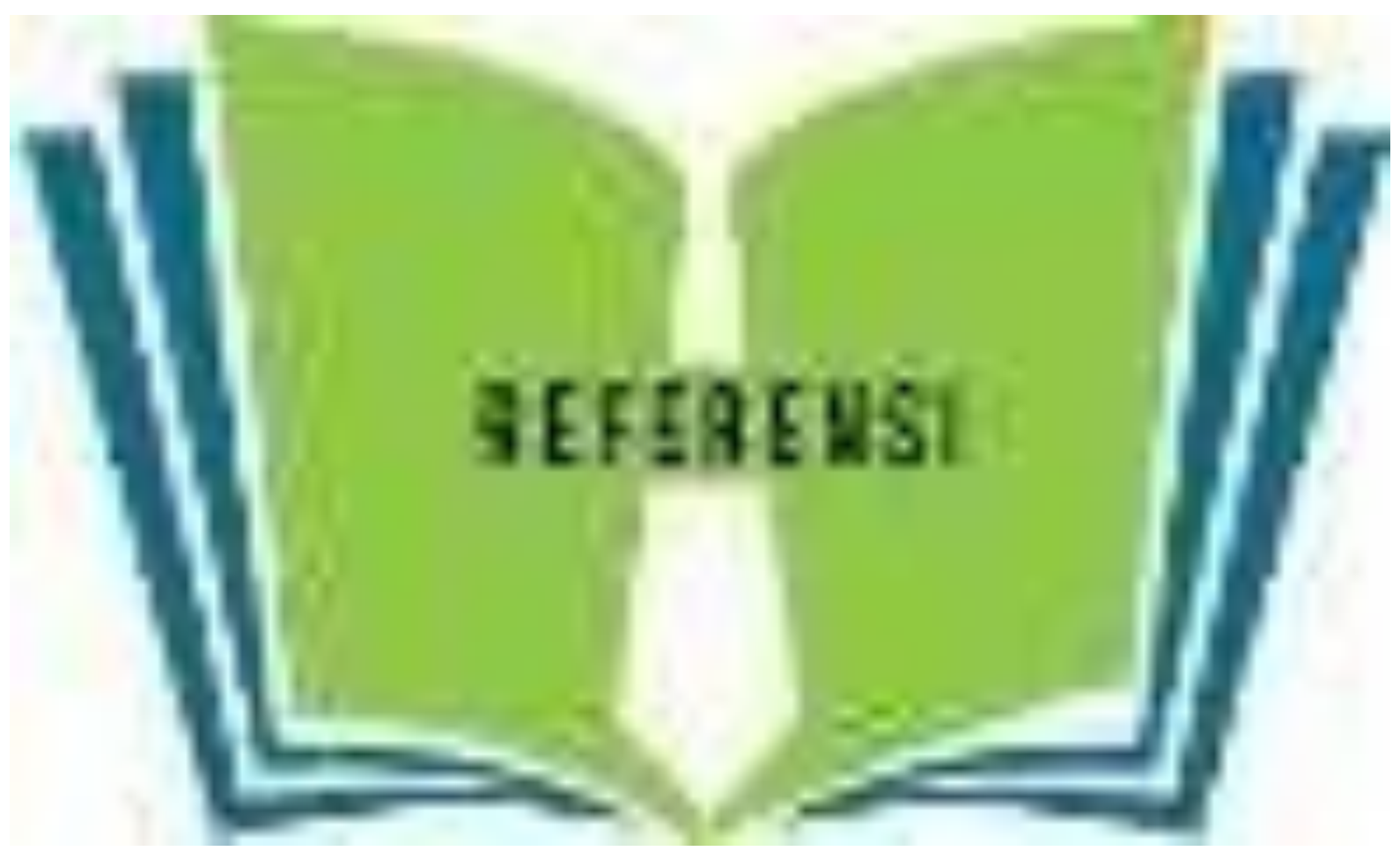

